Una semblanza de Ricardo Horvat

José María Schinocca

Question/Cuestión, Vol. 2, № 66, Agosto 2020

ISSN 1669-6581

https://perio.unlp.edu.ar/ojs/index.php/question/index

IICom-FPyCS-UNLP

\title{
UNA SEMBLANZA DE RICARDO HORVAT
}

\section{A STORIE ABOUT RICARDO HORVAT}

\begin{abstract}
José María Schinocca
Locutor Nacional y Docente de Periodismo.

Trabajos; Servicios de Noticias de Radio Nacional, América, Libertad,

Rivadavia, Continental y La Voz de Las Madres. Conductor los programas Primera Hora Continental. Vuelta de pagina y Utopistas del sur

Docencia en TEA periodismo general y periodismo deportivo. Instituto ORT y talleres de radio y locución en varias FM alternativas
\end{abstract}

\section{Resumen}

Ricardo Horvath, periodista, escritor y docente. Creador, productor, realizador y conductor de distintos ciclos radiofónicos, como Café, bar, billares. Autor de Memorias y recuerdos de Blackie, La trama secreta de la radiodifusión 
argentina, Cuba la oculta y ¿Qué hacer con la radio?, entre otras obras. El homenaje de José María Schinocca, un compañero de ruta.

\section{Palabras clave}

Radio, Periodismo, Creador, Comunicación

\section{Abstract}

Ricardo Horvath, journalist, writer and teacher. Creator, producer, director and host of different radio programs, such as Café, bar, billiards. Author of Memories and memories of Blackie, The secret plot of Argentine radio broadcasting, Cuba hides it and What to do with the radio? among other works. The tribute of José María Schinocca, a fellow traveler.

\section{Keywords}

Radio, Journalism, Creator, Communication

\section{Enlace}

https://go.ivoox.com/rf/55624213 